\title{
Comparing the analgesic effect of intranasal fentanyl and ketamine in children
}

\author{
Golikhatir Iraj', Montazer Seyed Hossein ${ }^{1 *}$, Aghilli Elham², Aminiahidashti Hamed ${ }^{1}$, Bozorgi \\ Farzad $^{1}$, Jahanian Fatemeh ${ }^{1}$ and Hosseininejad Seyed Mohammad ${ }^{1}$ \\ ${ }^{1}$ Assistant Professor, Department of Emergency Medicine, Mazandaran University of Medical Science, Sari, Iran \\ ${ }^{2}$ Emergency Medicine Resident, Mazandaran University of Medical Science, Sari, Iran
}

\begin{abstract}
Introduction: Pain control is one of the treatment priorities and the most important children's rights because children experience painful events since birth and during childhood due to common childhood illnesses or accidents. The aim of this study was to compare the analgesic effect of intranasal ketamine and fentanyl in children. Method: The present research is a double blind randomized clinical trial conducted on 80 children aged 3-13 years who were admitted to the Emergency Department of Sari Imam Hospital. The patients who met the inclusion criteria were randomly divided into two groups using random number generator and 40 patients were considered per group. Data were analyzed using SPSS, Mann-Whitney-U test and wilcoxon paired test. Findings: The findings showed that the analgesic effect of ketamine and fentanyl are similar among the studied children and there is no significant difference. In ketamine group there was significant difference between the mean of pain, systolic blood pressure, diastolic blood pressure, heart rate and respiratory rate variables before and after taking ketamine, according to Willcoxon statistics and sig. smaller than 0.05. In fentanyl Group, there was significant difference between the mean of pain, systolic blood pressure, heart rate and respiratory rate variables before and after taking fentanyl, according to Willcoxon statistics and sig. smaller than 0.05. There was no significant difference between ketamine and fentanyl analgesic effect in terms of parental satisfaction and there was also no significant difference between medical team's level of satisfaction with ketamine and fentanyl analgesic effect. Conclusion: Considering that the analgesic effect of intranasal ketamine and fentanyl on the pain control among the studied children is similar, their prescription is recommended. It is also recommended to simultaneously measure children's level of anxiety and effect of these drugs on their anxiety because children have different experiences of pain and anxiety affects measuring pain severity in future studies.
\end{abstract}

KEY WORDS: ANALGESIC, INTRANASAL, FENTANYL, KETAMINE, CHILDREN

ARTICLE INFORMATION:

*Corresponding Author:igk_47@yahoo.com

Received $1^{\text {st }}$ Oct, 2017

Accepted after revision $21^{\text {st }}$ Dec, 2017

BBRC Print ISSN: 0974-6455

Online ISSN: 2321-4007 CODEN: USA BBRCBA

Thomson Reuters ISI ESC and Crossref Indexed Journal

NAAS Journal Score 2017: 4.31 Cosmos IF: 4.006

- A Society of Science and Nature Publication, 2017. All rights reserved.

Online Contents Available at: http//www.bbrc.in/

DOI: $10.21786 / \mathrm{bbrc} / 10.4 / 24$ 


\section{INTRODUCTION}

Pain is one of the most common symptoms in patients admitted to the emergency room. Achieving desired analgesia and sedation before the procedures has become an elusive goal in many cases (Murphy et al., (2014).International Association of pain defined it as an unpleasant feeling and emotional experience associated with acute or potential tissue damage (Hazinski 2013). Children are usually brought to the emergency department due to painful diseases and injuries. Other diagnostic and painful or unpleasant therapeutic procedures may be required during the visits (Atkinson et al., (2009). Pain in children is more difficult than adults either in the evaluation or treatment process. This difficulty becomes more obvious when Intravenous analgesic is considered (Moore et al. (2010). Creating a practical approach to sedation and analgesia may vary in different parts of the world (Shahryariet al 2010 Majidi et al., 2017).

Many studies have been conducted on the analgesic effects of ketamine in the world. Many studies conducted on intranasal, oral and rectal administration of ketamine have shown that topical application of this drug is also possible. Many empirical evidence suggest that NMDA receptors exist in the central nervous system and peripheral nerves. Moreover, empirical studies have noted that the peripheral administration of NMDA receptor antagonists show analgesic effects of this drug (Hadayi M, Rezaeian M. (2011, Brian et al 2015).

Fentanyl is a potent opioid agonist that can be used in different ways. Fentanyl is the oldest synthetic opioid agonist and mainly exerts its effect on the hair receptor (Brian et al., (2015). Intravenous administration is the main method of medications to children but it is also stressful and painful and we sometimes need to spend a lot of time. Intramuscular injection is similar to the intravenous injection with the exception that longer period of time is required for the drug to exert its effect. According to the foregoing, intranasal and buccal methods seem to be more appropriate methods (Banks, et al. (2004). However, between these two methods, using buccal method requires need more interaction between the child and the therapist and even in voluntary cases of drug use, 56\% of the drug remains in the mouth. Nasal cavity holds a rich vascular network and since this vascular bed is easily accessible, it is easy to be managed. Onset and peak effect usually occurs after 3-5 minutes and within 10-15 minutes (Veldhorst, 2013).

Studies have shown that a wide range of intranasal ketamine doses has been used in clinical practice and further research is proposed to determine the optimal dose of intranasal ketamine for analgesia (Marcia et al. (2013). So far, various medications are presented and provided for this purpose. But ketamine, which is a receptor agonist has gained much popularity in this field (Majidi et al., 2017).

Fentanyl is a short-acting strong industrial drug and is now widely used for pain relief. Few studies have compared the effects of intranasal fentanyl and ketamine. Graudins et al., (2015) conducted a study in American Academy of Emergency Medicine (AAEM) and compared the effect of intranasal fentanyl and ketamine in children 3 to 13 years who suffered from organ damage and had pain severity of at least 6 out of 10 . The 40 children were assigned in each group in this comparison. As a result, a reduced pain which was reported in both groups was similar, but ketamine showed more side effects. Level of satisfaction with and side effects of ketamine and fentanyl was respectively $83 \%, 78 \%$ and $82 \%, 40 \%$. Prior to this study, there was no study on intranasal fentanyl and ketamine for pain control in children.

In a study in 2013 in the Department of Emergency Medicine of British Columbia Hospital, Andolfatto investigated the intranasal ketamine effect in reducing pain in patients admitted to the emergency department. This study was performed in patients older than 6 years. A total of 40 patients were enrolled in the study and the mean change in pain was $34 \mathrm{~mm}$ within 30 minutes and the average time for this reduction in pain was about 9.5 minutes. There were no reports of serious side effects during this time and all reported side effects were transient, requiring no intervention.

Murphy et al. (2014) conducted a study in the Department of Emergency Medicine at University College Dublin and studied intranasal fentanyl consumption for the treatment of acute pain in children. Patients were randomly selected and intranasal fentanyl was administrated for pain control and its efficacy was compared with intravenous medications. Side effects and level of satisfaction were also investigated. This study was carried out on children aged less than 21 years who weighed more than $10 \mathrm{~kg}$ with severe pain. Severity of pain was assessed every 5 minutes to 30 minutes and then at 30.60 and 120 minutes. A total of 30 patients were enrolled and the pain severity was dropped by about $13 \mathrm{~mm}$ after 120 minutes. There were no severe side effects, for which intervention was needed. Also, small sample size of some studies caused the results not to be generalized to the entire population (Yeaman et al., (2013). Also, different doses of these two drugs were used in studies on the effects of intranasal ketamine or fentanyl in pain control among children (Saunders et al., 2010).

In our country, no comparison has been made in this way. Since there has been no similar study in this regard so far in the country, similar studies conducted abroad are few and the results of these few studies cannot generalized to all areas yet. On the other hand, taking into 
account the speed and ease of use of the intranasal drug, we decided to compare the effect of intranasal fentanyl and ketamine as well as their effects and complications in pain management. The present study also aimed to achieve acceptable outcome with regard to recommending the use of these two drugs in the emergency department by measuring satisfaction of parents and medical team.

\section{MATERIAL AND METHODS}

This study is a double blind randomized clinical trial that was conducted on 80 children aged 3-13 years' old who were taken to Sari Imam Hospital. Individuals who were enrolled in the study were selected among all children aged 3-13 years who were admitted to emergency due to the trauma and needed remedial measures and painful procedures such as healing wounds with moderate to severe pain during procedure. The number of samples was considered 40 individuals for each group based on statistical formulas. Patients who met the inclusion criteria were randomly assigned in two groups using random number generator so that the number of children had relatively equal distribution at the end, allowing evaluation of the results for both age groups. A total of 40 patients were considered in each group. One group received Ketamine and the other one was given fentanyl. Among pain severity assessment scales, which are used at early age, FPS-R scale is a scale that is translated into 30 languages and can be used for free (Julie 2013).

VAS scale is also a measure commonly used in the age of 6 years, the patient shows the location of his/her pain on a horizontal line. Left and right sides of the line show point of no pain and unbearable pain, respectively. Pain score range is between the pain score in the left side and is expressed in millimeters. Based on the pain scales pain severity of 6 and higher shows moderate to severe pain. At the beginning of the project and during the procedure, FPS-R and VAS scales were respectively used to assess pain in children aged 3-6 and over 6 years. Eventually, after summarizing the pain assessment results and the effect of the drugs on it, qualitative evaluation of the results was performed.

According to ASA physical status classification standards, all ASA I and II class children were enrolled in the study. Also according to method of drug use, all children with severe colds, respiratory infections or major nasal damage, and all those with taking painkillers before referral, given the confounding effect on the evaluation of results, and contraindications for drugs, suspected cases of increased ICP, severe respiratory diseases or a history of seizure disorders were excluded. Also, after obtaining permission from the Medical Ethics Committee, registering the present trial in the Iranian database of clinical trials and providing adequate explanations on how to do pain management technique as well as obtaining consent letter from children's parents, patients were enrolled.

However, patients were not deprived of any treatment due to participation in this research and it does not cause any harm to them .Lidocaine was used for local anesthesia during the procedure. Both drugs produced by Rotemxmedica-Germany company, Ketamine and fentanyl were prepared by Saha Halal Pharmaceutical Company and Drug Administration of Mazandaran University of Medical Sciences, respectively. After the initial assessment and recording pain levels and vital signs at admission in the first questionnaire then in the second questionnaire during the procedure, the following standard recording and monitoring were performed: pulse rate (PR), respiratory rate (RR), blood pressure (BP), blood oxygen saturation (Sp02) and temperature body temperature $(\mathrm{T})$.

Drugs were already drawn into 1cc syringes, to have equal volume of drugs, appropriate to $10 \mathrm{~kg}$ weight. The syringe were named A and B and were given to the head of the pharmaceutical ward who was unaware of their contents. The drugs were later administrated to patients in a double-blind, randomized manner during the project. One group received $1 \mathrm{mg} / \mathrm{kg}$ intranasal ketamine and $1 \mathrm{mcg} / \mathrm{kg}$ intranasal fentanyl was administrated to another group. The procedure was started 5 minutes after administration is starting considering the time required for onset of action. The pain severity and vital signs were examined at 5, 15, 20, 30, 45 and 60 minutes in the studied patients, if necessary, an additional 1.4 dose was prescribed for pain control to at 15 minutes. In case of spo2 less than $92 \%$ for more than 10 seconds or apnea more than 20 seconds, jaw thrust maneuver and mask ventilation was started. Nausea and vomiting was measured by observing and questioning the patient and parents. Other side effects, including dizziness, and derealization were recorded by observing and questioning and each of them underwent treatment and monitoring based on the severity and type. Information was recorded by an individual (emergency resident or medicine specialists) who was unaware of the groups. Data analysis was carried out using SPSS v.16 and MannWhitney-U test and Willcoxon paired test.

\section{RESULTS AND DISCUSSION}

The mean \pm standard deviation of pain before taking Ketamine and fentanyl were respectively, 8.9, 8.93 and $0.93,0.92$ and there was no significant difference between Ketamine and fentanyl groups in terms of pain before taking these drugs based on Mann-Whitney $U$ z-statistic and sig. value of greater than 0.05. Thus, chil- 


\begin{tabular}{|c|c|c|c|c|c|c|}
\hline Variable & Group & Average & Number & $\begin{array}{l}\text { Standard } \\
\text { Deviation }\end{array}$ & $\begin{array}{l}\text { Mann- Whitney } \\
\text { Z statistics }\end{array}$ & Sig. \\
\hline \multirow{2}{*}{$\begin{array}{l}\text { Pre medication } \\
\text { pain }\end{array}$} & Ketamine & 40 & 8.90 & 0.93 & \multirow{2}{*}{$0.14-$} & \multirow{2}{*}{0.900} \\
\hline & Fentanyl & 40 & 8.93 & 0.92 & & \\
\hline \multirow{2}{*}{$\begin{array}{l}\text { Post medication } \\
\text { pain }\end{array}$} & Ketamine & 40 & 2.68 & 0.86 & \multirow{2}{*}{0.00} & \multirow{2}{*}{0.001} \\
\hline & Fentanyl & 40 & 2.68 & 0.86 & & \\
\hline
\end{tabular}

dren in both groups were not statistically different in terms of the premedication pain and are homogeneous.

The mean \pm standard deviation of pain after taking Ketamine and fentanyl were respectively, 2.68, 2.68 and 0.86, 0.86 and there was no significant difference between Ketamine and fentanyl groups in terms of pain after taking these drugs based on Mann-Whitney U z-statistic and sig. value of greater than 0.05 . Thus, children in both groups were not statistically different in terms of the post-medication pain and are homogeneous. In other words, it can be said that the analgesic effect of these drugs is similar in children is not significantly different (Table 1).

According to U Mann Whitney Test, mean \pm SD of systolic blood pressure before taking ketamine and fentanyl were 107.63, 107.38 and 5.43, 4.86, respectively. Based on U Mann Whitney Test z-statistic and sig. value of greater than 0.05 , there is no difference between the two groups of children in terms of blood pressure before using the drug. According to U Mann Whitney Test, mean \pm SD of diastolic blood pressure before taking ketamine and fentanyl were 66.38, 65.63 and 5.06, 4.83, respectively. Based on U Mann Whitney Test z-statistic and sig. value of greater than 0.05 , there is no difference between the two groups of children in terms of diastolic blood pressure before using the drug. Mean \pm SD of heart rate before taking ketamine and fentanyl were 108.30, 108.35 and 7.05, 7.49, respectively. Based on U
Mann Whitney Test z-statistic and sig. value of greater than 0.05 , there is no difference between the two groups of children in terms of heart rate before using the drug.

Mean \pm SD of respiratory rate before taking ketamine and fentanyl were 18.4,18.8 and 1.82,2.02, respectively and based on U Mann Whitney Test z-statistic and sig. value of greater than 0.05 , there is no difference between the two groups of children in terms of respiratory rate before using the drug.

Mean \pm SD of oxygen saturation before taking ketamine and fentanyl were 99.5, 99.55 and 0.96,0.85, respectively and based on U Mann Whitney Test z-statistic and sig. value of greater than 0.05 , there is no difference between the two groups of children in terms of oxygen saturation before using the drug. Thus, we conclude that children in two groups are homogeneous in terms of the above variables and there is no significant difference between them before treatment (Table 2).

Based on U Mann Whitney Test, mean \pm SD of systolic blood pressure after taking ketamine and fentanyl were $103.75,103.25$ and 4.63,5.13, respectively and based on U Mann Whitney Test z-statistic and sig. value of greater than 0.05 , there is no difference between the two groups of children in terms of systolic blood pressure after using the drug.

Mean \pm SD of diastolic blood pressure after taking ketamine and fentanyl were 64,65 and $4.56,4.24$, respec-

\begin{tabular}{|c|c|c|c|c|c|c|}
\hline Variable & Group & Number & Average & $\begin{array}{l}\text { Standard } \\
\text { deviation }\end{array}$ & $\begin{array}{l}\text { Mann-Whitney } \\
\text { Z statistics }\end{array}$ & Sig. \\
\hline \multirow{2}{*}{$\begin{array}{l}\text { Pre- systolic blood } \\
\text { pressure }\end{array}$} & Ketamine & 40 & 107.63 & 5.43 & \multirow{2}{*}{$1.86-$} & \multirow{2}{*}{0.062} \\
\hline & Fentanyl & 40 & 107.38 & 4.86 & & \\
\hline \multirow{2}{*}{$\begin{array}{l}\text { Pre diastolic blood } \\
\text { pressure }\end{array}$} & Ketamine & 40 & 66.38 & 5.06 & \multirow{2}{*}{$0.64-$} & \multirow{2}{*}{0.52} \\
\hline & Fentanyl & 40 & 65.63 & 4.83 & & \\
\hline \multirow{2}{*}{ Pre-heart rate } & Ketamine & 40 & 108.30 & 7.05 & \multirow{2}{*}{0.07} & \multirow{2}{*}{0.95} \\
\hline & Fentanyl & 40 & 108.35 & 7.49 & & \\
\hline \multirow{2}{*}{ Pre-RR } & Ketamine & 40 & 18.40 & 1.82 & \multirow{2}{*}{$0.76-$} & \multirow{2}{*}{0.45} \\
\hline & Fentanyl & 40 & 18.80 & 2.02 & & \\
\hline \multirow{2}{*}{$\begin{array}{l}\text { Pre- oxygen } \\
\text { saturation }\end{array}$} & Ketamine & 40 & 99.50 & 0.96 & \multirow{2}{*}{$0.05-$} & \multirow{2}{*}{0.96} \\
\hline & Fentanyl & 40 & 99.55 & 0.85 & & \\
\hline
\end{tabular}




\begin{tabular}{|c|c|c|c|c|c|c|}
\hline Variable & Group & Number & Average & $\begin{array}{l}\text { Standard } \\
\text { deviation }\end{array}$ & $\begin{array}{l}\text { Mann-Whitney } \\
\text { Z statistics }\end{array}$ & Sig. \\
\hline \multirow{2}{*}{$\begin{array}{l}\text { Post- systolic blood } \\
\text { pressure }\end{array}$} & Ketamine & 40 & 103.75 & 4.63 & \multirow{2}{*}{$0.69-$} & \multirow{2}{*}{0.4896} \\
\hline & Fentanyl & 40 & 103.25 & 5.13 & & \\
\hline \multirow{2}{*}{$\begin{array}{l}\text { Post diastolic blood } \\
\text { pressure }\end{array}$} & Ketamine & 40 & 0.64 & 4.56 & \multirow{2}{*}{$1.21-$} & \multirow{2}{*}{0.2268} \\
\hline & Fentanyl & 40 & 0.65 & 4.24 & & \\
\hline \multirow{2}{*}{ Post -heart rate } & Ketamine & 40 & 102.15 & 5.57 & \multirow{2}{*}{$1.54-$} & \multirow{2}{*}{0.1242} \\
\hline & Fentanyl & 40 & 0.100 & 5.83 & & \\
\hline \multirow{2}{*}{ Post-RR } & Ketamine & 40 & 17.45 & 1.50 & \multirow{2}{*}{$0.52-$} & \multirow{2}{*}{0.6063} \\
\hline & Fentanyl & 40 & 17.60 & 1.45 & & \\
\hline \multirow{2}{*}{$\begin{array}{l}\text { Post -oxygen } \\
\text { saturation }\end{array}$} & Ketamine & 40 & 99.70 & 0.72 & \multirow{2}{*}{$1.11-$} & \multirow{2}{*}{0.2666} \\
\hline & Fentanyl & 40 & 99.50 & 0.88 & & \\
\hline
\end{tabular}

tively and based on U Mann Whitney Test z-statistic and sig. value of greater than 0.05 , there is no difference between the two groups of children in terms of diastolic blood pressure after using the drug.

Mean \pm SD of heart rate after taking ketamine and fentanyl were 102.15,100 and 5.57,5.83, respectively and based on U Mann Whitney Test z-statistic and sig. value of greater than 0.05 , there is no difference between the two groups of children in terms of heart rate after using the drug.

Mean \pm SD of respiratory rate after taking ketamine and fentanyl were 17.45,17.60 and 1.5,1.45, respectively and based on U Mann Whitney Test z-statistic and sig. value of greater than 0.05 , there is no difference between the two groups of children in terms of respiratory rate after using the drug.

Mean \pm SD of oxygen saturation after taking ketamine and fentanyl were 99.70,99.50 and 0.72,0.88, respectively and based on U Mann Whitney Test z-statistic and sig. value of greater than 0.05 , there is no difference between the two groups of children in terms of oxygen saturation after using the drug. Thus, we conclude that there is no statistically significant difference between children in the two groups after taking the drugs and the effect of these drugs on children is similar in this study (Table 3).

Now, after examining the mean differences between studied variables in two groups of children, we investigate the differences between these variables in each group before and after drug use in this section. According to Willcoxon statistics and sig. value of smaller than 0.05 , there was statistically significant difference in the ketamine group among mean values of pain, systolic blood pressure, diastolic blood pressure, heart rate and respiratory rate before and after taking ketamine. In other words, ketamine is effective in reducing blood pressure (systolic and diastolic), heart rate and respiratory rate except for oxygen saturation variable (Table 4).

\begin{tabular}{|c|c|c|c|c|c|c|}
\hline \multirow{13}{*}{ Ketamine } & Drug type & Average & Number & $\begin{array}{l}\text { Standard } \\
\text { deviation }\end{array}$ & $\begin{array}{l}\text { Willcoxon } \\
\text { statistics }\end{array}$ & Sig. \\
\hline & Pre medication pain & 8.90 & 40 & 0.93 & \multirow{2}{*}{ 5.630- } & \multirow{2}{*}{0.00009} \\
\hline & Post-medicationpain & 2.68 & 40 & 0.86 & & \\
\hline & Pre medication systolicblood pressure & 107.63 & 40 & 5.43 & \multirow{2}{*}{ 3.489- } & \multirow{2}{*}{0.0005} \\
\hline & Post medication systolicbloodpressure & 103.75 & 40 & 4.63 & & \\
\hline & Pre-medicationdiastolicbloodpressure & 66.38 & 40 & 5.06 & \multirow{2}{*}{$2.747-$} & \multirow{2}{*}{0.0060} \\
\hline & Post-medicationdiastolicbloodpressure & 0.64 & 40 & 4.56 & & \\
\hline & Pre-medicationHeart ratePre & 108.30 & 40 & 7.05 & \multirow{2}{*}{$5.191-$} & \multirow{2}{*}{0.00009} \\
\hline & Post-medicationheart rate & 102.15 & 40 & 5.57 & & \\
\hline & Pre-medicationRR & 18.40 & 40 & 1.82 & \multirow{2}{*}{$4.359-$} & \multirow{2}{*}{0.00009} \\
\hline & Post-medicationRR & 17.45 & 40 & 1.50 & & \\
\hline & Pre- medication oxygen saturation & 99.50 & 40 & 0.96 & $1.232-$ & \multirow{2}{*}{0.2180} \\
\hline & Post- medication oxygen saturation & 99.70 & 40 & 0.72 & & \\
\hline
\end{tabular}




\begin{tabular}{|c|c|c|c|c|c|c|}
\hline \multirow{13}{*}{ Fentanyl } & Drug type & Average & Number & $\begin{array}{l}\text { Standard } \\
\text { deviation }\end{array}$ & $\begin{array}{l}\text { Willcoxon } \\
\text { statistics }\end{array}$ & Sig. \\
\hline & Pre-medication pain & 8.93 & 40 & 0.92 & $5.630-$ & \multirow{2}{*}{0.00009} \\
\hline & Post-medication pain & 2.68 & 40 & 0.86 & & \\
\hline & Pre-medication systolic blood pressure & 109.88 & 40 & 4.87 & $3.489-$ & \multirow{2}{*}{0.0005} \\
\hline & Post-medication systolic blood pressure & 103.25 & 40 & 5.13 & & \\
\hline & Pre-medication diastolic blood pressure & 65.63 & 40 & 4.83 & $2.747-$ & \multirow{2}{*}{0.0060} \\
\hline & Post-medication diastolic blood pressure & 0.65 & 40 & 4.24 & & \\
\hline & Pre-medication Heart Pre rate & 108.35 & 40 & 7.49 & $5.191-$ & \multirow{2}{*}{0.00009} \\
\hline & Post- medication heart rate & 0.100 & 40 & 5.83 & & \\
\hline & Pre- medication RR & 18.80 & 40 & 2.02 & $4.359-$ & \multirow{2}{*}{0.00009} \\
\hline & Post-medication RR & 17.60 & 40 & 1.45 & & \\
\hline & Pre-medication oxygen saturation & 99.55 & 40 & 0.85 & $1.232-$ & \multirow{2}{*}{0.2180} \\
\hline & Post-medication oxygen saturation & 99.50 & 40 & 0.88 & & \\
\hline
\end{tabular}

According to Willcoxon statistics and sig. value of smaller than 0.05 , there was statistically significant difference in the fentanyl group among mean values of pain, systolic blood pressure, heart rate and respiratory rate before and after taking fentanyl. In other words, fentanyl is effective in reducing blood pressure (systolic and diastolic), heart rate and respiratory rate except for diastolic blood pressure and oxygen saturation variable (Table 5)

Based on the Mann-Whitney test, mean \pm SD of parents' satisfaction with analgesic effect of ketamine and fentanyl were respectively 73.75, 75.25 and 7.40 6.79; so based on the Mann-Whitney z-statistic and sig. value of more than 0.05, there is no significant difference between parental satisfaction with the ketamine and fentanyl analgesic effect.

Mean \pm SD of medical team satisfaction with analgesic effect of ketamine and fentanyl were respectively 74.75, 75.75 and 5.06, 5.01; so based on the MannWhitney z-statistic and sig. value of more than 0.05, there is no significant difference between medical team satisfaction with the ketamine and fentanyl analgesic effect (Table 6).
The results showed that there is no significant difference between analgesic effects of these two drugs in studied children. These results are consistent with results obtained by Gradyns (2015) in America where the level of pain reduction was similar in both groups. The result of the current study are also consistent with the results of the study conducted by Yeamen et al., (2013) who examined the effects of fentanyl and ketamine on pain and pain caused by intraoperative ulcer and concluded that both fentanyl and ketamine are effective in pain relief and analgesia compared with placebo, but are not significantly different from each other: but the results of this study are inconsistent with results of the study conducted by (Julie 2013) in Iran, in which the difference between ketamine and fentanyl is relatively low and negligible and this effect has been reported to be due to the analgesic properties of ketamine.

The results of studies on the effects of fentanyl and ketamine are different, which could be due to different injury, choice of different patients, lack of blinding in the studies and type of the study design. The results showed that except for the oxygen saturation variable, ketamine

Table 6. Comparison of parents and the medical team satisfaction with analgesic effect of Ketamine and fentanyl based on the Mann-Whitney U test

\begin{tabular}{|l|l|c|c|c|c|l}
\hline Variable & Group & Number & Average & $\begin{array}{l}\text { Standard } \\
\text { deviation }\end{array}$ & $\begin{array}{l}\text { Mann Whitney } \\
\text { Z statistics }\end{array}$ & Sig. \\
\cline { 1 - 5 } \multirow{2}{*}{ Parental satisfaction } & Ketamine & 40 & 73.75 & 7.40 & \multirow{2}{*}{0.991} & \multirow{2}{*}{0.322} \\
\cline { 2 - 5 } & Fatanyl & 40 & 75.25 & 6.79 & \\
\hline \multirow{2}{*}{$\begin{array}{l}\text { Medical Team } \\
\text { Satisfaction }\end{array}$} & Ketamine & 40 & 74.75 & 5.06 & \multirow{2}{*}{$0.890-$} & 0.374 \\
\cline { 2 - 5 } & Fantanyl & 40 & 75.75 & 5.01 & & \\
\hline
\end{tabular}


was effective in reducing blood pressure (systolic and diastolic), heart rate and respiratory rate and fentanyl was also effective in reducing systolic blood pressure, heart rate and respiratory rate except for diastolic blood pressure and oxygen saturation variables. Very limited side effects were observed that were not tested due to being limited. Five derealization cases in the ketamine Group and three vomiting and three nausea cases in the fentanyl Group were reported. The results of the present study are consistent with the results of the study conducted by Gradyns (2015) who showed that ketamine has more side effects.

In a study on changes in respiratory rate, Javaherforooshet al., (2006)showed that ketamine and fentanyl lead to the highest and lowest respiratory rates, which may be due to the respiratory stimulant and respiratory depression effects of ketamine and fentanyl, respectively. In a study, (Tsze et al., (2012) showed that ketamine was well tolerated in pediatric pain management and one case led to vomiting. The results showed that the difference between the satisfaction of parents and the medical team of ketamine and fentanyl analgesic effect is not significant. Parents' average satisfaction with the analgesic effect of ketamine in children is $73.75 \%$ and medical team's average satisfaction with the analgesic effect of fentanyl was equal to $74.75 \%$. The same amount for ketamine and fentanyl was 83\% and $82 \%$, respectively in a study conducted by Gradyns et al. (2015).

In a study on the effects of intranasal fentanyl for pain relief in children with musculoskeletal trauma, Saunders et al. (2010) reported satisfaction percentage of 79\% and 74\% respectively for parents and the medical team. One of the limitations of this study include that patients might have usednarcotic or any other analgesic drug for pain relief prior to admission to the emergency center. So, this issue could affect the outcome of the research and that's why this issue should be considered in future studies and prevents the entry of similar cases to the study. Considering the small number of similar studies, further studies are needed to prove the effectiveness and compare the intranasal effect of these drugs. Another limitation was that pain was different for children because they had different experiences of pain and assess pain in children were not easy. Therefore, it is recommended to consider larger sample size in next studies and level of anxiety in children and the effect of these drugs on anxiety be measured simultaneously because children have different experiences of pain and anxiety is effective in measuring the severity of pain. Also, ketamine and fentanyl analgesic effects and side effects and different methods of administration should be investigated in future studies.

\section{REFERENCES}

Atkinson P, Chesters A, Heinz P. (2009). Pain management and sedation for children in the emergency department. BMJ. 30; 339: 4234

Banks, W. A., M. J. During, et al. (2004). Brain uptake of the glucagon-like peptide-1 antagonist exendin (9 39) after intranasal administration. J PharmacolExpTher. 309(2): 469-75.

Brian M. Radvansky, Khushbu Shah, Anant Parikh, Anthony N. Sifonios, Vanny Le, and Jean D. (2015). Eloy Role of Ketamine in Acute Postoperative Pain Management, Department of Anesthesiology and Peri-Operative Medicine. Rutgers-New Jersey Medical School.

Graudins A, Meek R, Egerton-Warburton D, Oakley E, Seith R. (2015). The PICHFORK (Pain in Children Fentanyl or Ketamine) trial: a randomized controlled trial comparing intranasal ketamine and fentanyl for the relief of moderate to severe pain in children with limb injuries. Ann Emerg Med. 65(3):248-254.

Hadayi M, Rezaeian M. (2011). The efficacy of Ketamine gargles on postoperative sore throat. Zahedan J Res Med Sci (ZJRMS).13(5): 12-16.

Hazinski MF. Analgesia, sedation, and neuromuscular blockade. 3 rd ed. Chapter 5: Nursing care of the critically ill child. Elsevier Mosby; 2013p.78.

Javaherforoosh F, Pipelzadeh M, Salary A, Zabihi A. (2006). Comparison of Preanesthetic Sedation after Intranasal Administration of Fentanyle, Ketamin and Midazolam. Armaghane Journal. 11(2): 19-27. (Persian)

Marcia L. Buck, Pharm.D. (2013). FCCP, FPPAG Options for Intranasal Procedural Sedation and Analgesia in Children. Pediatric Pharmacotherapy is available on the University of Virginia School of Medicine .9(8).

Moore A, Straube S, Derry SH, McQuay HJ. (2010). Chronic low back pain analgesic-A methodological minefield. PAIN, 149: 431-434.

Murphy A, O’Sullivan R, Wakai A. (2014). Grant TS Intranasal fentanyl for acute pain in children 1Paediatric Emergency Research Unit (PERU), Department of Emergency Medicine, National Children's Research Centre.

MajidiNejad S, Goudarzi L, Esmaeilian M, Heidari F. (2017). The Effect Ondansetron on Reducing Nausea Caused By Ketamine in Pediatric Patients Visiting Emergency Department; a Clinical Trial. Journal of Emergency Medicine Iran. 4(1): 15-19. (Persian)

Saunders M, Adelgais K, Nelson D. (2010).Use of intranasal fentanyl for the relief of pediatric orthopedic trauma pain. Department of Pediatric Emergency Medicine, Medical College of Wisconsin, Milwaukee, USA AcadEmerg Med. 17(11):1155-61.

Shahryari H, Alavi S.M, Ferasat Kish R, Motamed N, Karimi M. (2010). Comparison of propofol effect with Ketamine for sedation induction in pediatric patients who underwent cardiol catheterization. Iranian South Medical Journal .13(1): 16-23. (Persian).

Tsze D, Steele D, Machan J, Akhlaghi F, Linakis J. (2012). Intranasal Ketamine for Procedural Sedation in Pediatric Laceration Repair. Pediatric Emergency Care. 28(8):767-770. 
Veldhorst J. (2013). Intranasal delivery of rapid acting drugs:Studies of pharmacokinetics, effect, tolerability and satisfaction, UniversitairePers Maastricht. PhD Thesis: 141

Will Julie C. (2013). Preventable Hospitalizations and Emergency Department Visits for Angina, United States, 19952010. Preventing Chronic Disease. 10.
Yeaman F, Oakley E, Meek R, Graudins A. (2013). Sub-dissociative dose intranasal ketamine for limb injury pain in children in the emergency department1Southern Health Emergency Medicine Research Group, Southern Clinical School, Faculty of Medicine, Nursing and Health Sciences, Monash University, Clayton, VIC 3168, Australia Emerg Med Australas. 25(2): 161-7. 